\section{EREM 76/1}

Journal of Environmental Research, Engineering and Management

Vol. 76 / No.2 / 2020

pp. 111-117

DOI 10.5755/j01.erem.76.2.25411
The Analysis of EMAS Efficiency in Industrial Companies: A Case of Lithuania

\title{
The Analysis of EMAS Efficiency in Industrial Companies: A Case of Lithuania
}

\author{
Olga Anne*, Dovilè Aleknavičiūtè, Tatjana Paulauskienè, Rasa Viederytė \\ Klaipedda University, Herkaus Manto 84, 92294, Klaipėda, Lithuania
}

\section{Žaneta Stasiškienè}

Kaunas University of Technology, Institute of Environmental Engineering, K. Donelaičio 73, 44249 Kaunas, Lithuania

\section{Lilita Abele}

Liepaja University, Circular Economy Center, 14 Liela Street, Liepaja, Latvia

*Corresponding author: olga.anne@ku.lt

The contemporary progress in civilisation is combined with new scientific approaches, technological innovations and the huge and growing use of natural resources, which leads to their over-exploitation and, as a result, to their depletion. There is an opinion that without further regulation of economic growth and excessive harvesting of resources, the entire ecosystem of the Earth can be irreparably destroyed. The 2030 Agenda is based on the decoupling principle, which means that the economic growth of the manufacturing and service sectors must be faster than the consumption of natural resources and energy. To this end, countries around the world have developed and are still pursuing different environmental measures, such as regulations, laws and orders, taxes, etc. The most popular management systems in Europe are ISO 14001 and EMAS. The newest analyses reveal that a large number of companies that have received an EMAS certificate are not willing to renew their registration after some time and the reasons are not very clear yet. The article discusses the methods for environmental impact assessment, sustainable industry development and motivations for resources efficiency. The study of the selected three production companies operating in Lithuania and currently using a pollution prevention tool - the environmental management system - is presented and discussed aiming to evaluate the effectiveness of resources consumption.

Keywords: resources, EMAS, decoupling. 


\section{Introduction}

An undesirable effect of resource use can appear in every stage of its exploitation: mining, direct usage and manufacture of products. To keep exploiting natural resources and save their quality or even existence, it is mandatory to set strict sustainable goals and monitor the progress.

The United Nations International Resource Panel encourages industrial society to use the decoupling method for resources evaluation. The resource usage here is compared with institutions' economic growth while trying to reduce the inefficient and harmful exploitation, thus in the meantime improving humankind existence and reducing the negative impact on the environment. In decoupling, land, water, energy, etc. can be considered as resources (UNEP, 2011).

To reduce the negative impact on the environment, the concept of the integrated pollution prevention control is widely applied. It includes live and inanimate nature. This mechanism binds institutions to implement different tools, which prevent and reduce the irrational natural resources consumption (European Commission, 2012).

As for self-initiative manners, institutions often invoke environmental management systems (Neugebuer, 2012). It gives the opportunity for companies to continuously improve their environmental indicators and reduce the negative impact on the environment (Salim, 2017).

There are two most common systems in Europe, and one of them is the Eco-Management and Audit Scheme (EMAS). Unfortunately, while the number of companies certified by other systems increases, companies that have an EMAS accreditation tend not to keep it for the future (Merli and Preziosi, 2017). Although ISO 14000 and EMAS have the same target, i.e., to develop sustainable economy, the EMAS environmental management system requires to meet more strict requirements (Ziegler and Nogareda, 2009).

The EMAS impact on resource efficiency is poorly studied nationwide (Matuszak-Flejszman et al., 2019). Studies about EMAS consider not the system's efficiency, but the causes why companies tend to refuse further certification (Merli and Preziosi, 2017; Merli et al., 2018; Alvarez-Garcia et al., 2018).

\section{Study Objects and Methods}

Three manufacturing companies of Lithuania using one of the climate change prevention tools - the environmental management system EMAS - were selected for this study. The chosen companies have implemented and operate the EU Eco-Management and Audit Scheme (EMAS). Different types of companies, organisational and manufacturing ones, have the possibilities to implement EMAS. In Lithuania, only seven institutions have been certified according EMAS. One of them is the organisational type, while the others are the manufacturing type. Currently, only three of six manufacturing companies still have a valid EMAS certificate:

1 The first company is the leading waste management company in Lithuania, which carries out secondary materials and municipal waste assembly, transportation and processing. The company was established in 1995. Currently, the company works in sixteen municipalities in Lithuania and has one of the best equipment in the Baltic region, which is able to process and prepare 200 thousand tonnes of secondary materials for recycling per month.

2 The second company is a private knitwear company, which was established in 1970. It manufactures top and bottom knitwear, such as sweaters, scarfs, hats for women, men, children and other textile products for home. This company is acknowledged as the best knitwear manufacturing company in the country.

3 The third company is a branch of a joint Lithuanian-foreign firm, which manufactures juice drinks in Lithuania. At the moment, it is the most modern juice factory in Lithuania that offers more than 40 different kinds of juice, nectar and juice drinks, which are bottled in four different packages. It was established in 1997.

The decoupling method was applied to estimate the use of resource efficiency by EMAS implementation. The method of evaluation of resource decoupling was taken from the Organisation for Economic Co-operation and Development (OECD) and the suggested formula, where the factor of decoupling is counted, was used. The evaluation consists of the analysis of environmental pressure and driving forces: 


decoupling factor $=1-\frac{\left(\frac{E P}{D F}\right)_{\text {end of period }}}{\left(\frac{E P}{D F}\right)_{\text {start of period }}}$

Where: $D F$ is the driving force; $E P$ is environmental pressure.
When the factor of decoupling is zero or negative, there is no decoupling. This means that the growth of the speed of resource usage for the chosen period is faster or the same as driving forces. If the decoupling factor is above zero, then decoupling exists and the usage of the resource is slower than the economic growth. The decoupling rate is also divided by intensity (Shuai et al., 2016).

Table 1. Decoupling factor value by intensity

\begin{tabular}{l|c|c|c|c|c|c}
\hline Factor's value & {$[-1-0]$} & {$[0-0.2]$} & {$[0.2-0.4]$} & {$[0.4-0.6]$} & {$[0.6-0.8]$} & {$[0.8-1]$} \\
\hline Intensity & None & Poor & Weak & Normal & Obvious & Strong \\
\hline
\end{tabular}

The decoupling factor was evaluated for these specific resources, taking into consideration the companies' use of electricity, diesel, gasoline, water, liquid gas, and natural gas. For the decoupling evaluation of the first and the second company, manufactured production was used as the driving force; and for the third company, the collected quantity of waste was used, because this company does not manufacture any products. In the first company's case, the data of 2005-2009 were analysed before EMAS installation and after the installation in 2010-2016. The resources analysis of the second company was done for 2011-2013 before EMAS and for 2014-2016 after acquiring it. In the third company's case, data analysis was made for 2007-2009 and 2010-2016 accordingly before and after EMAS implementation.

The single-factor statistical analysis was applied to count resource usage for one unit/piece of production (or collected kilogram of waste) and the results were compared before and after EMAS implementation.

\section{Results}

The conventional method of resource consumption was applied to define the ratio of the material amount for one unit of production. After EMAS implementation, the first company reduced diesel consumption; therefore, the amount of resource used to make one piece of knitwear was reduced as well. In case of the second company, EMAS implementation did not affect the situation, i.e., the average consumption of resources to make one litre of juice drinks did not change. The third company considered the average use of water, electricity, and diesel consumption for one kilogram of collected waste. After EMAS adaption, the use of these resources did not change.

The decoupling method differs from the conventional one and allows us to analyse the intensity of resource use. Therefore, the results are different. The first company in its operation uses such resources as liquid gas, gasoline, diesel, water, natural gas and electricity. To minimise the impact on the environment, the company adapted EMAS in 2010.

The decoupling factors were calculated based on the resource usage before and after EMAS implementation for each targeted company. Every case was different. The first company succeeded in separating its production growth from resource consumption after EMAS implementation for gasoline and liquid gas; the received results were stronger by the decoupling factor value after EMAS (Fig. 1). The decoupling factor for the other resources - diesel, water, natural gas and electricity - was lower than after EMAS implementation, and the natural gas decoupling factor after EMAS was even negative, which means that the growth rate of natural gas usage was faster than the production growth rate. In the second company's case, the driving force component (litres for the manufactured drinks) 
Fig. 1. The first company decoupling factors for each used resource before and after EMAS

The first company decoupling factor before and after EMAS

\begin{tabular}{r|} 
Liquid gas \\
Gasoline \\
Diesel \\
Water \\
Natural gas \\
Electricity
\end{tabular}

$-0.2$

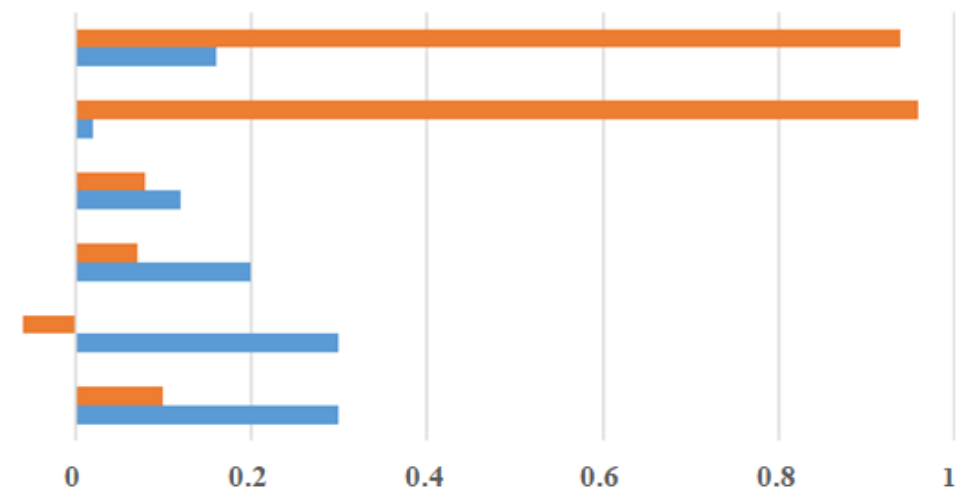

- After EMAS n Before EMAS

Fig. 2. The second company decoupling factors for each used resource before and after EMAS implementation

The second company decoupling factor before and after EMAS

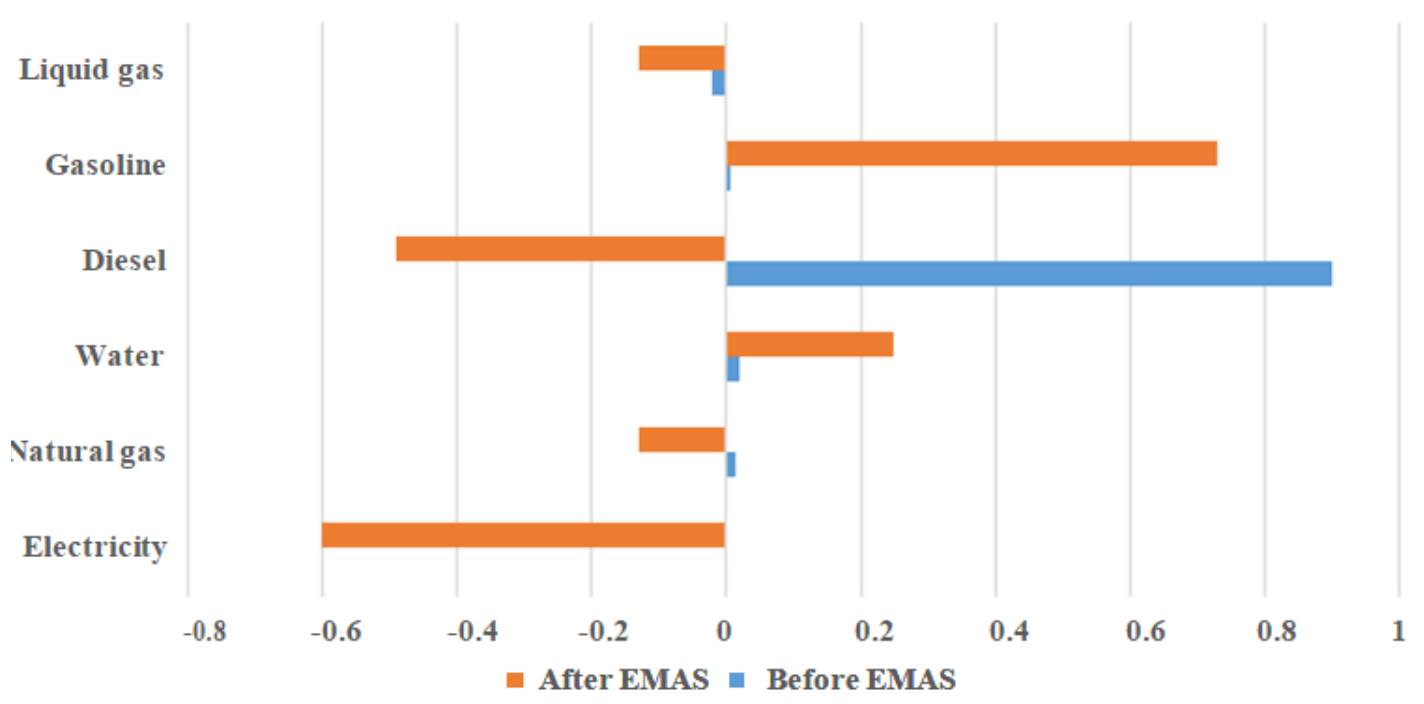


Fig. 3. The third company decoupling factors for each used resource before and after EMAS implementation

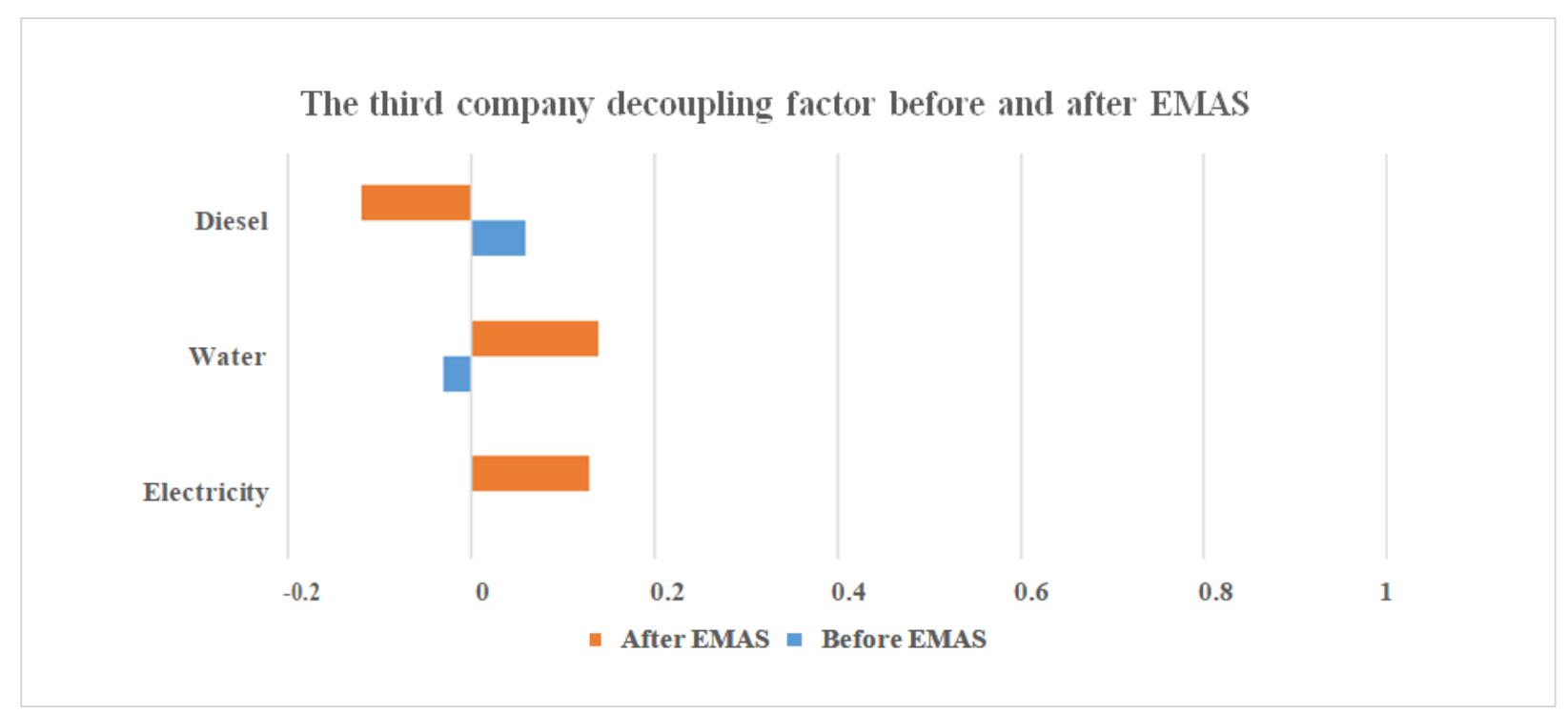

decreased every year over the studied period. In the meantime, not all resources consumption decreased in line with it (Fig. 2). Liquid gas, diesel, and electricity decoupling factor rates after EMAS implementation were lower than before and even negative. Only gasoline and water consumption decoupling rates improved after EMAS.

In case of the third company (Fig. 3), consumption of water and electricity showed higher decoupling factor rates after EMAS. For example, the consumption of diesel before EMAS was not high, but had a positive decoupling factor. After the implementation of the system, the decoupling factor became negative in the studied period.

\section{Discussion}

The analysis of the impact of the EMAS system on the resource consumption in Lithuanian manufacturing companies revealed that this environmental management system can partially improve environmental performance. According to the decoupling factor, every studied company improved consumption efficiency of two resources after EMAS implementation.
This resulted in the financial benefit for the companies and, of course, contributed to reduction of the negative impact on the environment, which is the main goal of environmental management system (Iraldo et al., 2014). Currently, EMAS is not a popular system, but the performed analysis proved that EMAS implementation could become more efficient if the companies had the EMAS certification for a longer period of time (Weiss, 2014).

The environmental management system can be effective if the company avoids the organisational, human resources or legal mistakes at the beginning of the system implementation (Nawrocka, 2008). This requires responsible apprehension about the plando-check-act principle. By using this cycle, activities and targets have to be planned very carefully and strictly. This cycle is constant and helps the institution to improve its processes and activities. At the same time, the environmental management system is an investment. It requires time, financial input and appropriate human resources. All targeted institutions avoid mistakes and, in the most successful cases, the certification costs pay off in one year.

The pressure to implement an environmental management system from other competitive institutions 
could explain some negative results of the resource consumption in the analysed companies. Therefore, companies do not set resolute goals or do not try to improve environmental indicators through efficiency of the resource consumption and use the environmental management systems only as a symbol to obtain acknowledgement (Darnall et al., 2008). Such manufacturing companies improve their position and competiveness in the market - they get more appreciation, better relationship with customers (Lundgren and Zhou, 2017; Merli et al., 2018). This brings financial benefit, but only temporary, which has happened with some Lithuanian industrial companies (the number of certified companies decreased from six to three). Eventually, some companies experienced a shortage of the inner forces and resources to keep the certification valid (Darnall et al., 2008).

Furthermore, EMAS efficiency depends on the companies' activity, and in this study, the third company widely differs from the other companies. As it was presented, the third company is a good example of an organisation that publishes only a few environmental indicators and uses a small number of resources but see the perspective in the implementation of the environmental management system. Therefore, the data

\section{References}

Álvarez-García, J., del Río-Rama, M. de la C., Saraiva, M., \& Ramos Pires, A., 2018. The influence of motivations and barriers in the benefits. An empirical study of EMAS certified business in Spain. Journal of Cleaner Production, vol. 185, p. 62-74. https:// doi.org/10.1016/j.jclepro.2018.03.023

Darnall, N., Henriques, I., Sadorsky, P. (2008). Do environmental management systems improve business performance in an international setting? Journal of International Management, vol. 14(4), p. 364-376. https://doi.org/10.1016/j.intman.2007.09.006

European Commission Determination, which declares rules of data collecting, BAT information documents preparation and their quality assurance guides that are reglamented By European Parliament and Board directive 2010/75/ES about industrial pollution (2012/119/ES), 2012.

Iraldo F., Testa F., Frey M. (2014). Environmental Management System and SMEs: EU Expierience, Barriers and Perspectives. Institute for Environmental and Energy Policy and Economics, Milano, Italy. about the usage of resources should be optimised globally (Mazzi et al., 2012). Until such optimisation, evaluation of EMAS efficiency between different companies is not really convincing. An enterprise with EMAS has a decisive tool for an assessment of its environmental policy performance based on natural resources savings and their effective consumption.

\section{Conclusions}

The analysis showed that there were two positive decoupling cases in each studied company after EMAS implementation, which proved efficiency of the EMAS impact on the use of resources. The first company managed to improve water and electricity consumption. The second improved gasoline and liquid gas consumption and the third company improved gasoline and water consumption. This means that in the analysed companies the growth rate of the consumption of certain resources is lower than the growth rate of the company's economy. Such a partially positive impact has been found after EMAS implementation. These results have been considered as the most important motivation to continue the improvement of the implemented environmental management system.

Lundgren T., Zhou W. (2017). Firm performance and the role of environmental management. Journal of Environmental Management, vol. 203, p. 330-341. https://doi.org/10.1016/j.jenvman.2017.07.053

Matuszak-Flejszman A., Szyszka B., Jóhannsdóttir L., 2019. Effectiveness of EMAS: A case study of Polish organisations registered under EMAS. Environmental Impact Assessment Review 74 (2019), p. 86-94. https://doi.org/10.1016/j.eiar.2018.09.005

Mazzi A., Toniolo S., Catto S., De Lorenzi V., Scipioni A. (2017). The combination of an Environmental Management System and Life Cycle Assessment at the territorial level. Environmental Impact Assessment Review. https://doi.org/10.1016/j.eiar.2016.11.004

Merli R., Lucchetti C. M., Preziosi M., Acrese G., 2018. Causes of Eco-Management and Audit Scheme (EMAS) stagnation and enabling measures to stimulate new registrations: Characterization of public administrations and private-owned organizations. Journal of Cleaner Production, vol. 190, p. 137-148. https://doi.org/10.1016/j.jclepro.2018.03.303 
Nawrocka D. (2008). Environmental supply chain management, ISO 14001 and RoHS. How are small companies in the electronics sector managing? Corporate Social Responsibility and Environmental Management Journal, Vol. 15, Issue 6, p. 349360. https://doi.org/10.1002/csr.176

Neugebaue F., 2012. EMAS and ISO 14001 in the German industry - Complements or Substitutes? Journal of Cleaner Production, vol. 37, p. 249-256. https://doi.org/10.1016/j.jclepro.2012.07.021

Salim K. H., Padfield R., Hansen B. S., Mohamad E. S., Syayuti K. Y. A., Tham H. M., Papargyropoulou E., 2017. Global Trends in Environmental Management System and IS014001 Research. Journal of Cleaner Production, vol. 170, p. 645-653. https://doi. org/10.1016/j.jclepro.2017.09.017

Shuai C., Jiao L., Song X., Shen L. (2017). Decoupling Analysis on the Relationship Between Economic Development and Environ- ment Degradation in China. In: Wu Y., Zheng S., Luo J., Wang W., Mo Z., Shan L. (eds) Proceedings of the 20th International Symposium on Advancement of Construction Management and Real Estate. https://doi.org/10.1007/978-981-10-0855-9_106

United Nations Environment Programme (UNEP) (2011). Decoupling Natural Resource Use and Environmental Impacts from Economic Growth.

Weiss D., Skinner A., Smyth M., Slupska M., Kahlenborn W. (2015). Final Report Supporting the Evaluation of the Implementation of EMAS. Publications Office of the European Union, Luxembourg.

Ziegler, A., Nogareda, J. S., 2009. Environmental management systems and technological environmental innovations: Exploring the causal relationship. University of Zurich, Zuroch Open Repository and Archive. https://doi.org/10.1016/j.respol.2009.01.020 